\title{
The Emerging Underclass in the Russian Federation: Income Dynamics, 1992-1996*
}

\author{
Michael Lokshin and Barry M. Popkin \\ University of North Carolina at Chapel Hill
}

\section{Introduction}

The transition to a market economy by the countries of Eastern Europe and the former Soviet Union has been a dramatic move from a relatively stable economic condition with equal income distribution to one with uncertainty, political and economical instability, and sharp polarization in resource distribution. The sweeping economic reforms have led the Russian Federation to eliminate most, if not all, general subsidies and significantly reduce subsidies and payments to the poor. The privatization of many activities and the process of allowing prices and exchange rates to fluctuate caused rapid economic and social changes. Since the onset of the economic transition, the establishment of a social safety net and the need to mitigate the social costs associated with the transition from a planned state economy to a market-oriented economy have been a major concern in the countries of the former Soviet Union. The political support of reforms in these countries after the end of communism and the question of political stability become vital to their governments. Poverty and inequality are among the factors that determine the distribution of political power. As A. B. Atkinson and J. Micklewright note, "The legitimacy of governments may be called into question if too large a gap opens between rich and poor.', 1

We use seven rounds of longitudinal data to examine this economic transformation and its social consequences with respect to poverty. We show that new population groups with totally different standards of living are surfacing. On one end are the Russian capitalists, so-called new Russians, who enjoy a high standard of living, even for developed countries. At the other end, a significant proportion of the population survives on income close to the subsistence level. The notion of a culture of poverty, widely used in Western economic literature, and the concept of an underclass appear to be emerging. This study shows the income dynam- 
ics that have arisen provides some sense of who constitutes this emerging underclass and presents evidence of the seriously misleading results associated with a cross-sectional analysis of poverty in this region.

To date, most analyses of the social dimensions of this transformation have been based on cross-sectional information and have been unable to answer the relevant questions regarding the social costs of the transitions. ${ }^{2}$ Only recently in Western Europe and the United States have longitudinal data sets become available for research. The Panel Study of Income Dynamics launched in the United States in 1968, the German Socio-Economic Panel started in 1984, and the British Household Panel Study of 1988 are examples of longitudinal data studies. Based on these and other panels, scientists have begun to gain new insights into the patterns, causes, and consequences of poverty. Scholars increasingly have shown that time must be accounted for in the study of poverty. The prevailing view on poverty as a static phenomenon based on an assumption that the poor are behaviorally separate from the rest of society has led to an oversimplification of the nature of poverty. Consequently, it is commonly held that "the majority of the poor today walks along economic paths that are familiar to their parents and which, most probably, will be trodden by most of their children as adults and parents in the future."'3

This study of Russian poverty shows the opposite. While there is an emerging underclass, most periods of poverty are relatively short. Though only a small percentage of Russian families stay poor all their lives, this underclass must be carefully understood.

As we show for Russia, poverty can no longer be considered by using a static method that divides families into categories of poor and nonpoor. Instead, poverty should be studied from a dynamic perspective that recognizes that periods of poverty are finite. This approach allows the more appropriate linkage of macro- and microeconomic analyses of poverty and the development of an understanding of the causal roles played by structural and personal characteristics. Moreover, different policies may be needed to address transitory and long-term poverty problems.

\section{Methods}

\section{The Data}

The Russian Longitudinal Monitoring Survey (RLMS), the first and only nationally representative sample of households in the Russian Federation, provides the basis for this research. The survey comprises seven rounds conducted in September 1992 (round 1), February 1993 (round 2), August 1993 (round 3), November 1993 (round 4), December 1994 (round 5), October 1995 (round 6), and October 1996 (round 7). Over 6,000 households were surveyed in phase 1 (rounds 1-4), while approximately 4,000 households from a different panel were surveyed in phase 2 (rounds 5-7). The data were weighted across the rounds to ensure comparability. 
Faculty at the Carolina Population Center at the University of North Carolina at Chapel Hill (UNC-CH) have headed this effort. Phase 1 data were collected by the State Statistical Office (Goskomstat) of the Russian Federation in collaboration with the Russian Center for Preventive Medicine, the Institute of Sociology, Russian Academy of Sciences, and Paragon Research International. Phase 2 was carried out with a new set of families, in collaboration with the Institute of Sociology, Russian Academy of Sciences, the Institute of Nutrition, Russian Academy of Medical Sciences, and Paragon Research International. ${ }^{4}$

The initial sample of households for phase 1 of the survey was identified from a stratified three-stage cluster sample of residential addresses. Cities as well as urban and rural portions of rayons (political and geographic units about the size of counties in the United States) were the area units selected in the first stage. Probability proportionate to size (PPS) sampling was used to select the rayons. The rayons were stratified by the eight regions and by the percentage of the urban population within each region. Within each area chosen in the first stage, a sample of 10 voting districts was randomly chosen, again by PPS systematic selection, from a geographically ordered list of voting districts located in that area. Finally, within the boundaries of each selected voting district, a list of dwellings and households was developed by the UNC-CH team using visual inspection, based on lists that included addresses (such as voting lists) only as an initial guide. Adjustments were made for communal apartments and adult dormitories, where many households share one address. From the list of households, a systematic sample of 20 was drawn.

The second phase of the survey (1994-96) followed similar multistage clustering. The first cluster included three self-represented urban regions and 35 other primary sampling units (PSUs). According to the sampling researchers involved in these designs, the second phase had about 65 PSUs while the first phase had only 20 . Thus, there was considerably more clustering in the first phase. The procedures for selecting secondary sampling units and households were similar in the two phases, except that in the second phase census lists were used as a first step in which more detailed mapping and checks were implemented at the local level to collect the final lists of households. From phase 1, 3,763 families are represented in all four rounds. For the second phase, the number of families interviewed in three rounds was 2,887 .

\section{Methodology: Measures and Definitions}

Total household income. Total monthly disposable household income is used in the analysis. It includes wages and salaries, social security transfers, private transfers, in-kind income, and income from home production. No attempt has been made to estimate the value of subsidies to housing and utilities. Great care was taken to collect comparable measures of income over all rounds of the RLMS. The focus is on total 
household income because poverty is defined in Russia, as in most countries, on the basis of household welfare.

The poverty line. The Russian Federation has adopted a measure of poverty comparable to that of the United States. That is, a food basket based on nutritional criteria is developed for each age-gender group. This basket is priced out, and the average propensity to purchase food is used to increase this cost to the overall poverty line for each age-gender group. The cutoff for poverty is based on a level of nutritional intake requirements defined by the World Health Organization and Food and Agriculture Organization and adjusted slightly for the Russian Federation.

Studies of poverty in Russia have a long tradition. Most have focused on a minimum budget and subsistence wage or similar measures of minimum levels of living. ${ }^{5}$ In the mid-1950s, under the Khrushchev government, a minimum subsistence level measured by the Family Budget Surveys of the Goskomstat was used. ${ }^{6}$ This measure used an absolute-income-level index based on a large basket of goods and services ranging from food to items such as holidays. The minimum subsistence level related more to a consumption norm than a poverty index and indeed the term "poverty" (bednost) was not used until the dissolution of the USSR and the construction of the Western-style subsistence-level poverty line that is used here.

We use the official poverty line of the Russian Federation, a food basket developed for a set of age-gender groupings for all regions in the country. ${ }^{7}$ The critique that could be raised against this method is that the use of national average prices and constant food baskets fails to capture regional adjustments and compositional adjustments through relative price changes. Recently the government has begun work to incorporate regional adjustments in this food basket, which we do not use. However, economy-of-scale adjustments developed as part of this recent work are incorporated. ${ }^{8}$

Measures of persistent and transitory poverty. Moving from static to dynamic analyses of poverty in Russia requires the use of measures that will reflect dynamic components of poverty such as the duration of a poverty spell and household-income dynamics. This study focuses on the most widely used approach to measuring persistent and transitory poverty. ${ }^{9}$ This method uses a share of the population with income below the poverty threshold in $x$ out of $n$ time periods to estimate chronic poverty, and it is highly sensitive to the length of the observation period. As the period is lengthened, there is an increasingly reduced chronic poverty segment. In addition, there are censoring problems. ${ }^{10}$ Data do not allow one to determine when a poverty spell actually began. However, the RLMS data sets are unique in that the first wave of the survey was launched shortly after the economic reform process began in Russia. 
This marked the beginning of almost all poverty spells. There is potential for some censoring since a lower level of poverty did exist prior to the 1992 economic reforms. ${ }^{11}$ Consequently, the chronic poverty measure slightly underestimates the real proportion of the persistently poor because people whose poverty spells started before the beginning of the time series and people whose spells started in the middle of the survey are not included in the chronically poor group.

This approach uses the strength of the survey data to provide some sense of the shifts going on in the Russian Federation. We do not have adequate information to understand poverty spells fully. ${ }^{12}$

Classification of families into poverty categories. For each of the first four rounds of the RLMS, there are 16 different possible classifications for each family in the sample. Families are classified as never poor, poor for one round, poor for some combination of two or three of the rounds, or poor for all four rounds of phase 1 . Similarly in phase 2, there are three rounds, and families are classified as never poor, poor for one round, poor for two rounds, or poor for all three rounds. In addition, we differentiate between households classified as never poor and all households whose income rose above the poverty line for at least one round. This allows us to understand another dimension of Russian income dynamics - the emergence of a wealthy group.

Thus, based on the categorizations above, we label a family as persistently poor if their income lies below the poverty line for all rounds of phase 1 and phase 2. Families are defined as persistently rich when their income is greater than two times the designated poverty line for all rounds of the RLMS. As noted above, there will be fewer chronically poor families in phase 1 since the period of coverage is longer.

In following this approach, we are very much in the tradition initiated by Greg J. Duncan and others. As noted by Duncan et al., "Above all, the static dichotomy of 'poor' versus 'non poor' is very misleading and needs to be replaced by at least four dynamic categories of economic position-persistent poverty, transitional poverty, the economically vulnerable, and the financially secure."'13

\section{Income and Income Inequality Dynamics}

Four dynamic aspects of poverty are critical for understanding the structure of Russian poverty: the degree of income inequality within the poor subsample, the duration of a poverty spell, the difference in absolute income among poverty groups, and income variability for every category.

\section{Income Inequality}

Unequal income distribution among the poor provides a strong indication of their heterogeneity of well-being. We begin with an analysis of the 


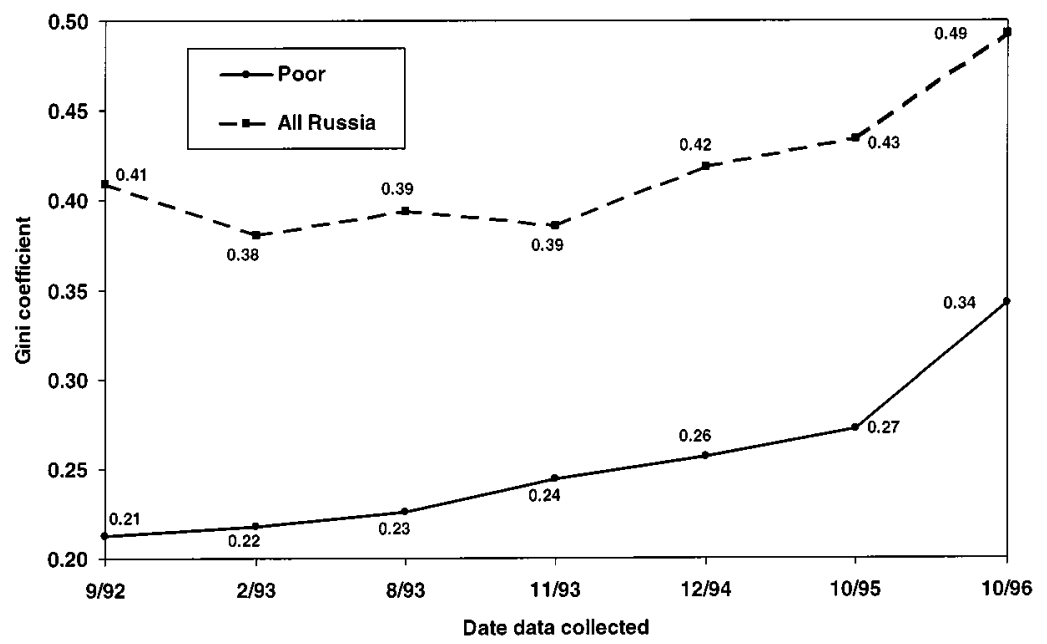

FIG. 1.-Gini coefficient for families with income below the poverty line and for the entire Russian population, RLMS rounds 1-4 (September 1992-October 1996).

distribution of absolute income in relation to the poverty line for the Russian poor. We conclude this section with an analysis of variation in income of poor Russian households as a measure of stability of income for different categories of Russian families.

Gini coefficients are used to demonstrate the shift in income inequality in Russia during the period covered by the RLMS. The polarization of income for the total population and for the poor is presented in figure 1. Income inequality is very high for the total Russian population and there was a Gini ratio of about .49 in 1996. The level of income inequality for poor households is high and is associated with a high within-group income variability.

\section{Income Dynamics}

Figure 2 shows the distribution of Russian households by type of income dynamics for phases 1 and 2 of the RLMS. Almost half the Russian families $(48.8 \%$ ) in phase 1 (rounds 1-4) stayed above the poverty line for the full 14 months of survey coverage. These families, which we designate as never poor, are Duncan's economically secure. More than $8 \%$ had an income at least double the poverty line. These numbers are comparable with the results from the second panel of the survey that spanned 23 months (33.5\% and $14.1 \%$, respectively).

We also find that a significant percentage of the population experienced poverty at least once during the period covered. The structure of 
(a) Rounds 1-4

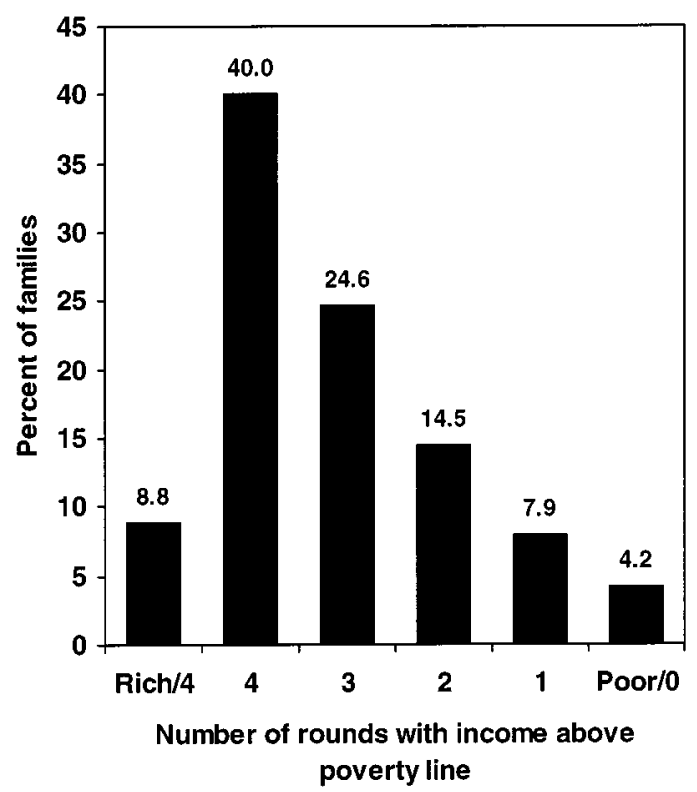

(b) Rounds 5-7

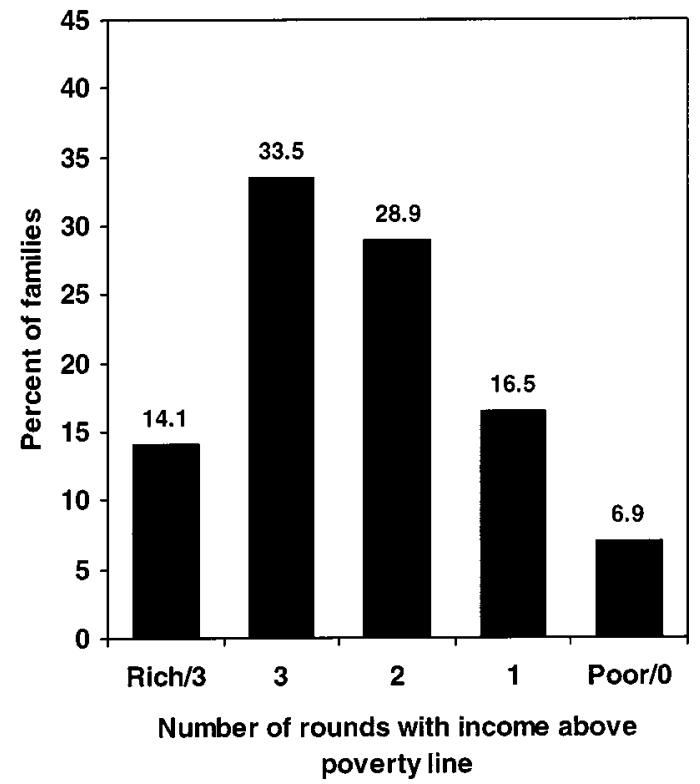

FIG. 2.-Distribution of Russian families by type of income dynamics: (a) RLMS rounds 1-4 (September 1992-November 1993); (b) rounds 5-7 (December 1994-October 1996). 
poverty is highly heterogeneous. The income of a large percentage of poor households ( $48.0 \%$ of the universe of poor households) dropped below the poverty line only once in rounds $1-4$. These are the occasionally poor $^{14}$ or economically vulnerable. ${ }^{15}$ Transitionally poor families are those that experienced poverty twice during phase 1 . Thus, $28.3 \%$ of poor families fall into this category. We designate the $15.4 \%$ of the families whose income was above the poverty line only once during phase 1 as recurrently poor. Finally, only $8.2 \%$ of the poor were persistently poor during all four rounds between September 1992 and November 1993.

The more recent data from phase 2 of the RLMS confirm these results. In this phase, transitionally poor families have an income above the poverty level for only one of three rounds, and the recurrently poor category is dropped. Although the group of persistently poor is larger (13.3\% of the total poor sample), some of these families would not be in this category had we had more time periods in the second sample. In rounds 5, 6, and 7 of the RLMS, 55.6\% of poor families were occasionally poor.

\section{Difference in Absolute Income}

The next point is to understand the income shares of these groupings relative to the poverty line. Living on an income permanently below the poverty line is difficult, but there are also important issues related to the severity of poverty. Who suffers the most? What groups are most vulnerable and need greater protection? To answer these questions, we examine the income distribution among different classes of the poor.

Figure 3 shows the proportion of income for each demographic grouping of the rich and the poor relative to the poverty line. This supports the common opinion that people who are persistently poor suffer the most. These families not only experience longer poverty spells, but their income is significantly lower than that of other households. The persistently poor from both phases of the survey survived on an income of almost half the minimum subsistence level and would be termed poor under most definitions. For example, the permanent-income approach, which takes into account the possibility for a family to save and borrow, would still put the household in the same category. Their income-toneeds ratio would be without a doubt lower than unity.

The recurrently poor in phase 1 have an average income per period that is below the poverty line. In contrast, the occasionally and transitionally poor have experienced some economic hardship, but their overall income reserves allow them to smooth out the occasional drops in their economic well-being. Average income for the occasionally poor was slightly above the poverty line. The same is not expected for the persistently and recurrently poor. In phase 2 , those who were poor in three rounds are the only group with an income deficit. 
(a) Rounds 1-4

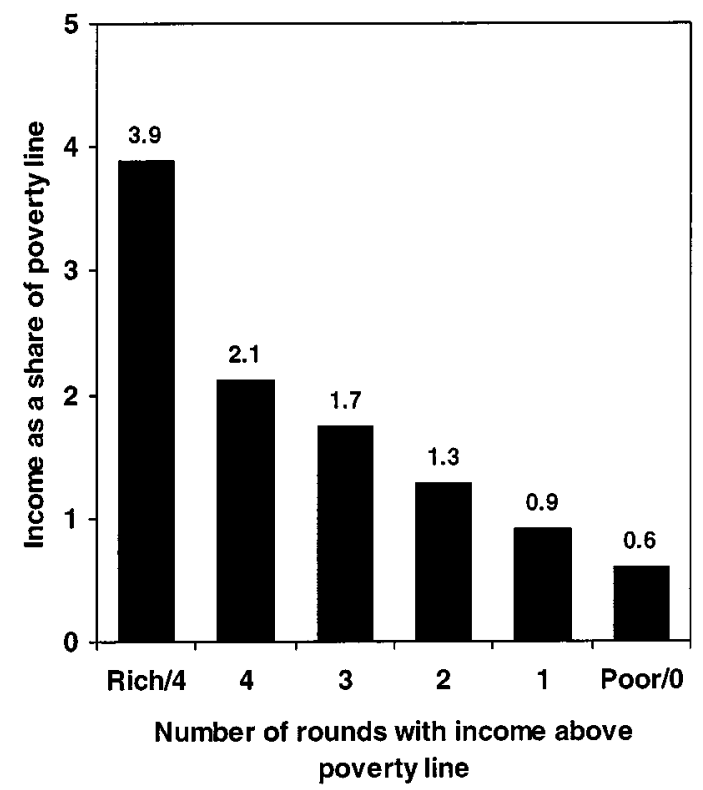

(b) Rounds 5-7

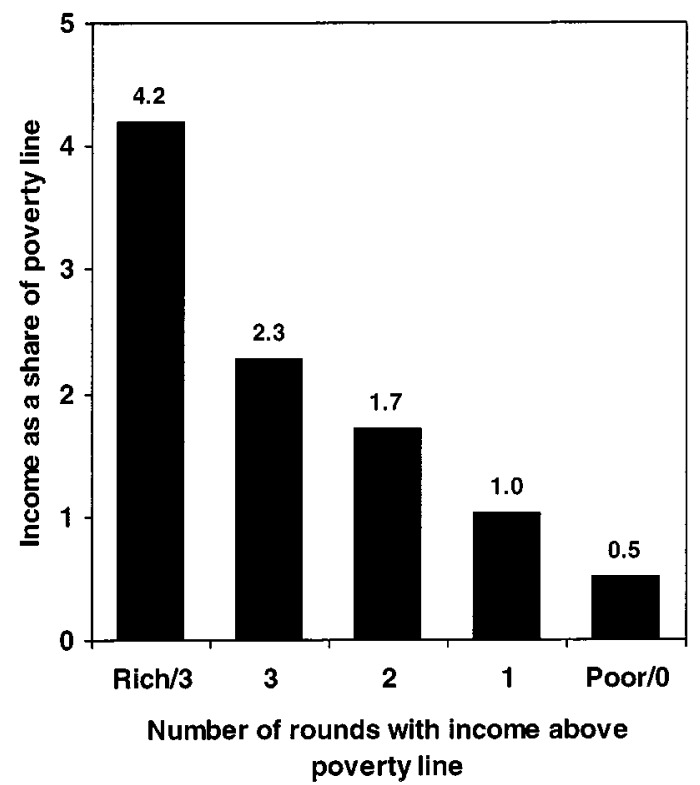

FIG. 3.- Income as a share of Russian family poverty line distribution categorized by type of income dynamics: (a) RLMS rounds 1-4 (September 1992November 1993); (b) rounds 5-7 (December 1994-October 1996). 


\section{Income Variation}

Being poor means different things for families with different degrees of economic mobility. The duration of a poverty spell and absolute income depend on the shifts over time in income relative to the poverty line. As we show in figure 4 , income variability is much smaller for the persistently poor and the very rich. Those who are poor transitionally or occasionally have much greater income variability as shown in the coefficient of variation.

Most of the income variation was experienced by transitionally and recurrently poor families. Families with the higher levels of income variation have the highest probability of changing their income status by moving from one category to another. For such families, the snapshot of short-term income distribution can be totally different from the picture of long-run economic conditions and opportunities. Finding the trigger events that make households exit from or enter into poverty would provide the basis for a poverty-prevention policy. Such an analysis is beyond the scope of this article.

The relatively stable income of the persistently poor in phases 1 and 2 (38.3 and 47.97 coefficient of income variation, respectively) is a direct indicator of the emerging Russian underclass (see fig. 4). Thus, the structure of Russian poverty can be characterized as essentially nonuniform. This heterogeneity is reflected in several observations. First, income distribution within the group of poor is more unequal than within the general population. Second, the duration of poverty spells varies among the different categories of Russian poor. Third, income variation over time for the households from the subgroups of poor is very different.

\section{The Poor, Who Are They?}

The previous section gave some sense of the income distribution of the poor and the volatility of income in the various clusters. In this section, we examine whether the six groupings of families categorized by income dynamics for rounds 1-4 and five groupings of families for rounds 5-7 are differentially associated with various social and economic indicators. There are two main perspectives in exploring the problem. First, it is important to understand whether specific segments of the Russian population are likely to experience different types of income dynamics. Second, we wish to determine whether the different income dynamics groupings can be distinguished in terms of the people affected. We use information collected in round 1 of phase 1 and round 5 of phase 2 to investigate the structural and individual composition of Russian poverty.

Most studies of poverty have found that the demographic (type of family, level of education, and age of head of household) and spatial factors of poverty are associated. We use the longitudinal data of the RLMS to study the multivariate relationships between the main factors that determine the income status of Russian households. 
(a) Rounds 1-4

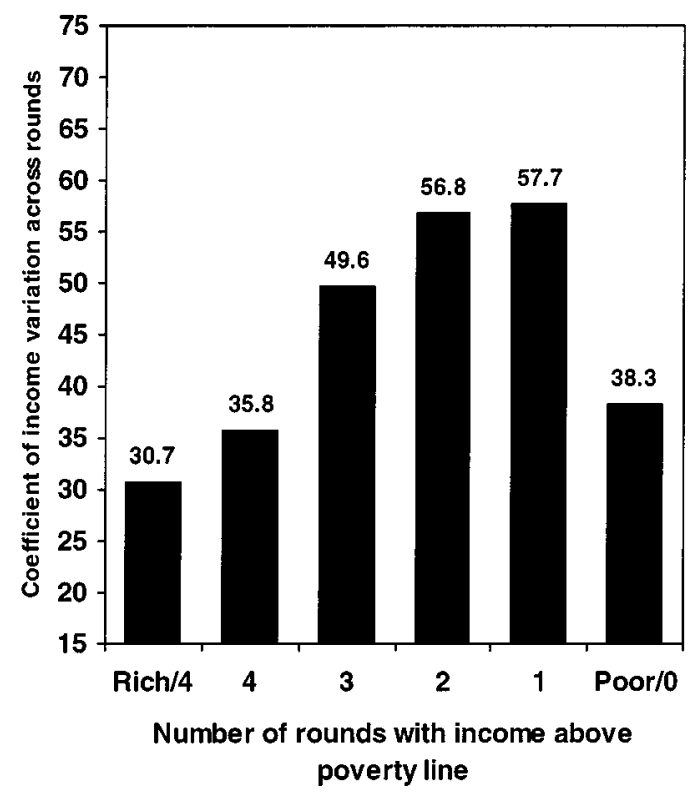

(b) Rounds 5-7

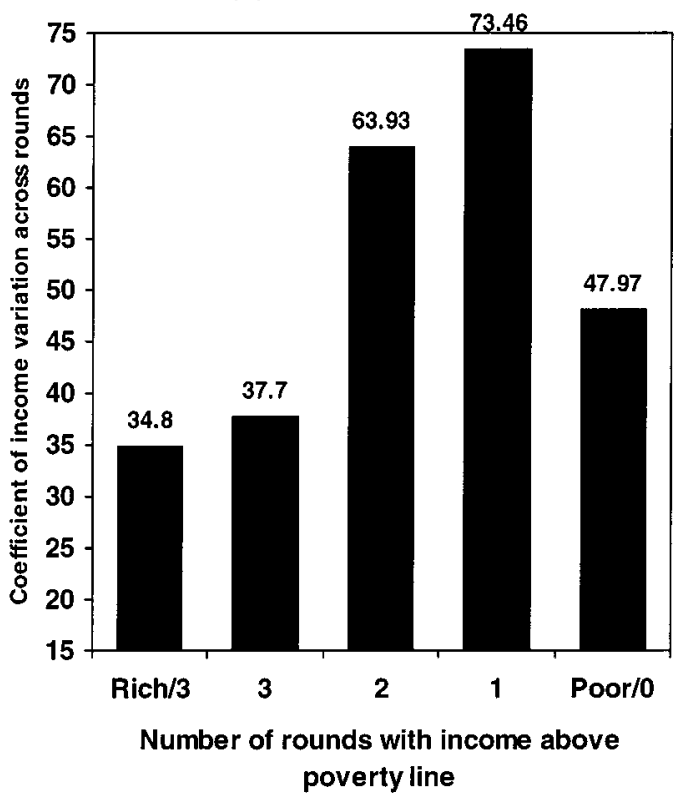

FIG. 4.- Mean coefficient of family income variation across rounds, categorized by type of income dynamic: (a) RLMS rounds 1-4 (September 1992November 1993); (b) rounds 5-7 (December 1994-October 1996). 


\section{Empirical Model}

The basic model for our multivariate-income-dynamic analysis is

$$
\begin{aligned}
& Y_{t i}=X_{t i} \beta+\zeta_{t i} ; t=2, \ldots, T_{i}, i=2, \ldots, N, \\
& \zeta_{t i}=\mu_{i}+\epsilon_{t i}+v_{t},
\end{aligned}
$$

where $Y_{t i}$ is the dichotomous variable that assumes a value 1 if the household is in poverty in the period $t$ and 0 if it is not, $X_{t i}$ is a $1 \times K$ vector of independent variables that can vary over time, and $\beta$ is the unknown vector of coefficients that needs to be estimated. The disturbance term $\zeta_{t i}$ consists of three components: $\mu_{i}$ represents the unobserved characteristics that vary from household to household but are constant through time- the so called individual-specific effects $-v_{t}$ is the unobserved factor that varies with time but stays the same for all households in the sample, and $\epsilon_{t i}$ represents unobserved characteristics that vary across the households and through time. The assumption is made that $\mu$ and $\epsilon$ are identically distributed, mutually independent, random variables with means equal to zero and standard deviations of $\sigma_{\mu}$ and $\sigma_{\epsilon}$, respectively.

We deal with the unobserved "time-specific" heterogeneity, that is, with the correlation in the error terms associated with $v_{t}$ by introducing the set of dummy variables for every survey round. Equation (1) then becomes

$$
\begin{aligned}
& Y_{t i}=X_{t i} \beta+\Gamma_{t}+\zeta_{t i} ; t=1,2, \ldots, T_{i}, i=1,2, \ldots, N, \\
& \zeta_{t i}=\mu_{i}+\epsilon_{t i},
\end{aligned}
$$

where $\Gamma_{t}$ is a $1 \times(T-1)$ vector of time-dummy variables; $X_{t i}$ consists of five dummy variables for each family demographic category, excluding the category "other"; two dummy variables indicating the location of the household, with the households from rural Russia as a reference group; two dummy variables for different levels of education-high school and technical and vocational education-excluding individuals with a university degree; a continuous variable for household head's age; a dummy variable indicating the household head's employment status; and a set of variables for interactions among the main parameters.

For several reasons, the random-effects-probit model is used for the estimation of the coefficients in equation (2). First, we can argue that most of the independent variables in equation (2) were considered exogenous in previous cross-sectional studies. Thus, an assumption of no correlation between the explanatory variables and the error term is valid for our case. ${ }^{16}$ Next, the dichotomous nature of the dependent variable makes it difficult to use the fixed-effect method since extensions of the fixedeffect estimator to the probit model or other dichotomous dependentvariable models were not very satisfactory. ${ }^{17}$ 
The random-effects-probit model is a maximum-likelihood function method applicable under the assumption of the normal distribution of the error term $\zeta_{t i}$. The observed dependent variable $Y_{t i}$ that represents the poverty status of the household in period $t$ is defined by the following system of equations:

$$
Y_{t i}= \begin{cases}0 & \text { if } Y_{t i}^{*} \leq L_{i} \\ 1 & \text { if } Y_{t i}^{*}>L_{i},\end{cases}
$$

where $Y_{t i}$ is the total household income in period $t$ and $L_{i}$ is the household structure specific real poverty line.

If we let

$$
h=\frac{1}{\sigma_{\epsilon}}, \rho=\frac{\sigma_{\mu}^{2}}{\left(\sigma_{\mu}^{2}+\sigma_{\epsilon}^{2}\right)}, B_{t i}=X_{t i} \beta+\Gamma_{t} \text {, and } \bar{\mu}_{i}=\frac{\mu}{\sigma_{\mu}},
$$

then

$$
h Y_{t i}^{*}=h B_{t i}+\left[\frac{\rho}{1-\rho}\right]^{-.5} \bar{\mu}_{i}+h \epsilon_{t i} .
$$

The conditional probability of being poor at time period $t$ was shown to be: ${ }^{18}$

$$
P\left(Y_{t i}=0 \mid \bar{\mu}_{i}\right)=\Phi_{t i}=\Phi\left(-h B_{t i}-\left[\frac{\rho}{1-\rho}\right]^{-.5} \bar{\mu}_{i}\right),
$$

and the corresponding probability of staying out of poverty is equal to 1 $-P(\cdot)$.

If experiencing poverty in 1 year is independent of whether the household has been poor previously, then the probabilities in the form of equation (5) can be multiplied together to obtain the joint probability of following a certain income-dynamic path. However, we would expect that the current level of family well-being is related to previous poverty status, $\rho$, or the interhousehold variance $\sigma_{\mu}^{2}$ is not zero; then the joint probability must be calculated taking into account these correlations. The generalization of equation (5) on the case of $T$ years for the particular household $Y_{i}=\left[Y_{1 i}, Y_{2 i}, \ldots, Y_{T i}\right]$ becomes

$$
P\left(Y_{i}\right)=\int_{-\infty}^{+\infty} \prod_{t=1}^{T} \Phi\left\{\left[h B_{t i}+\left(\frac{\rho}{(1-\rho)}\right)^{-.5} \bar{\mu}_{i}\right]\left[2 Y_{t i}-1\right]\right\} f\left(\bar{\mu}_{i}\right) d \bar{\mu}_{i},
$$


and the likelihood function for the longitudinal sample of $N$ households is then

$$
L=\prod_{i=1}^{N} P\left(Y_{i}\right), \text { where } i=1, \ldots, N
$$

The integral in equation (6) was approximated numerically using hermite integration. The conditional probabilities for different socioeconomic groups of households to exhibit certain types of income dynamics were calculated based on equation (6) by the maximization of likelihood function in the form of equation (7). Results of the estimations for rounds 1-4, February 1992-November 1993, and similar results for rounds 5-7, December 1994-October 1996, are presented in appendix table A1. Estimations are based on the sample of 3,523 households with 14,037 observations for rounds $1-4$ and on the sample of 2,417 households with 7,251 observation for rounds 5-7.

\section{Demographic Category}

Table 1, part A presents the simulation results for the distribution of income dynamics for selected demographic categories. We divide all families into six demographic categories: single-parent families (96\% are single-mother families in Russia), families with three or more children, families headed by pensioners, nuclear families (those with two parents and one or two children), families consisting only of prime-age adults (adults between age 25 and retirement), and families that fall into none of these categories. Important differences are clear. For example, singleparent families are twice as likely to be persistently poor as nuclear families are. Similarly, families with three or more children are in an even worse situation. For them the probability of being persistently poor is more than triple that of a nuclear family.

In contrast, families of pensioners and households that consist of prime-age adults are in a much better position. Less than $1 \%$ of pensioners' families are persistently poor. Almost $70 \%$ of them never experienced poverty during the survey period. Families consisting only of prime-age adults had the greatest likelihood of being placed in the always-rich category.

The poverty patterns vary markedly among groups. The groups most likely to experience poverty tend not to encounter it in its most severe forms. A fifth of the households with more than three children experienced poverty twice during the four rounds of phase 1. A meaningful proportion of nuclear families $(17.8 \%)$ also belong to this transitionally poor category. In comparison, only $7.3 \%$ of pensioners' families are transitionally poor.

Overall, for the 14 months covered by rounds $1-4$, two-thirds (60.6\%) 
TABLE 1

Simulation of the Distribution of Russian Households by Income Dynamics GroupINGS

A. Rounds 1-4, September 1992-November 1993

\begin{tabular}{|c|c|c|c|c|c|c|}
\hline & \multicolumn{6}{|c|}{ Type of Income Dynamics } \\
\hline & Rich & $\begin{array}{l}\text { Never } \\
\text { Poor }\end{array}$ & $\begin{array}{l}\text { Once } \\
\text { Poor }\end{array}$ & $\begin{array}{l}\text { Twice } \\
\text { Poor }\end{array}$ & $\begin{array}{c}\text { Three } \\
\text { Rounds } \\
\text { Poor }\end{array}$ & $\begin{array}{l}\text { Always } \\
\text { Poor }\end{array}$ \\
\hline \multicolumn{7}{|l|}{ Family demographic: } \\
\hline $\begin{array}{l}\text { Single mother }=\text { parent family* } \\
\text { Family with more than three }\end{array}$ & 3.2 & 23.2 & 25.5 & 21.4 & 16.3 & 10.1 \\
\hline children $\dagger$ & 2.5 & 15.7 & 22.3 & 22.8 & 20.6 & 15.8 \\
\hline Family of pensioners & 9.9 & 59.2 & 20.2 & $\begin{array}{r}7.0 \\
7.3\end{array}$ & 2.6 & .7 \\
\hline Nuclear family§ & 7.0 & 32.5 & 27.5 & 17.8 & 10.5 & 4.8 \\
\hline Family of prime-age adults & 9.9 & 35.2 & 27.2 & 15.8 & 8.4 & 3.5 \\
\hline Other & 7.6 & 38.4 & 26.1 & 15.3 & 8.6 & 4.0 \\
\hline \multicolumn{7}{|l|}{$\begin{array}{l}\text { Head of household employment } \\
\text { status: }\end{array}$} \\
\hline Employed & 7.5 & 33.8 & 26.4 & 16.9 & 10.3 & 5.1 \\
\hline Unemployed & 5.2 & 31.2 & 26.1 & 18.7 & 12.3 & 6.4 \\
\hline \multicolumn{7}{|l|}{ Head of household education: } \\
\hline High school & 6.9 & 44 & 24.1 & 13.5 & 7.7 & 3.7 \\
\hline Technical & 7.4 & 35.9 & 25.6 & 16.2 & 9.9 & 5.0 \\
\hline University & 13.1 & 42.2 & 24.3 & 12.8 & 6.0 & 2.3 \\
\hline \multicolumn{7}{|l|}{ Type of settlement: } \\
\hline Metropolitan & 11.0 & 45.4 & 23.9 & 11.8 & 5.7 & 2.2 \\
\hline Other urban & 7.7 & 37.5 & 25.3 & 15.5 & 9.3 & 4.7 \\
\hline Rural & 7.5 & 44.7 & 23.9 & 13.1 & 7.3 & 3.4 \\
\hline
\end{tabular}

B. Rounds 5-7, December 1994-October 1996

\begin{tabular}{|c|c|c|c|c|c|}
\hline & \multicolumn{5}{|c|}{ Type of Income Dynamics } \\
\hline & Rich & $\begin{array}{l}\text { Never } \\
\text { Poor }\end{array}$ & $\begin{array}{l}\text { Once } \\
\text { Poor }\end{array}$ & $\begin{array}{l}\text { Twice } \\
\text { Poor }\end{array}$ & $\begin{array}{c}\text { Three } \\
\text { Rounds } \\
\text { Poor }\end{array}$ \\
\hline \multicolumn{6}{|l|}{ Family demographic: } \\
\hline Single mother $=$ parent family* & 4.5 & 24.1 & 27.3 & 24.8 & 19.3 \\
\hline Family with more than three children $\dagger$ & 1.1 & 15.2 & 23.5 & 29.1 & 31.2 \\
\hline Family of pensioners $\ddagger$ & 13.6 & 49.2 & 23.9 & 10.1 & 3.3 \\
\hline Nuclear family§ & 7.1 & 24.2 & 29.0 & 24.0 & 15.7 \\
\hline Family of prime-age adults & 13.1 & 25.1 & 29.0 & 20.9 & 11.9 \\
\hline Other & 7.7 & 28.5 & 28.8 & 21.7 & 13.4 \\
\hline \multicolumn{6}{|l|}{ Head of household employment status: } \\
\hline Employed & 8.4 & 26.4 & 28.3 & 22.4 & 14.5 \\
\hline Unemployed & 8.2 & 25.7 & 27.9 & 22.5 & 15.7 \\
\hline \multicolumn{6}{|l|}{ Head of household education: } \\
\hline High school & 7.0 & 31.3 & 27.6 & 20.7 & 13.4 \\
\hline Technical & 8.4 & 27.3 & 28.7 & 22.0 & 13.7 \\
\hline University & 18.4 & 37.6 & 24.5 & 13.2 & 6.5 \\
\hline \multicolumn{6}{|l|}{ Type of settlement: } \\
\hline Metropolitan & 27.8 & 43.2 & 19.2 & 6.9 & 2.0 \\
\hline Other urban & 8.2 & 33.8 & 28.2 & 19.1 & 10.7 \\
\hline Rural & 7.6 & 23.50 & 27.8 & 23.7 & 17.3 \\
\hline
\end{tabular}

* Includes households with one prime-age female living with children and in some cases with pensioners.

$\dagger$ Includes households that are not single-parent families.

$\$$ Includes families of pensioners.

$\S$ Includes families with two parents and one or two children. 
of nuclear families experienced poverty at least once. The percentage increases to $73.5 \%$ among single-parent families; for families with three or more children, the proportion is even higher (81.8\%). Thus more than $70 \%$ of Russian children have lived in households where needs exceeded income. Children suffer disproportionately from the consequences of poverty.

The general relationships between poverty status and family demographic characteristics in the 1994-96 rounds (table $1 b$ ) are similar to those in the first four rounds. Families with three or more children are most likely and pensioners are least likely to be persistently poor. Although the demographic family type is one of the major factors in determining family income behavior, the contrast in probabilities of being poor is less well-defined among the households from phase 1 that are never poor, occasionally poor, and transitionally poor, as well as households that are never or occasionally poor during phase 2 .

\section{Education}

The educational level of the household head, as expected, is important. Tables $1 a$ and $1 b$ demonstrate the distribution of income by educational status of the household head. The pattern observed in 1992-93 continues in the second phase of the survey. Families in which the household head holds a university degree are much less likely to be in poverty than families with less-educated household heads, and they are more likely to be classified as rich or never poor. However, the differences between the income status of the household heads with high school and technical levels of education are much smaller than might be expected. Once again, as with the family demographic categories, education is not associated with the income dynamic groupings for families with income below the poverty line during one survey round.

\section{Types of Settlement}

As expected, families who live in Moscow or St. Petersburg are far less likely to be poor and more likely to be classified as rich or never poor. This is consistent with most economic data on new investment opportunities and privatization patterns. These two cities, so far, are the main recipients of foreign- and domestic-investment flows and the rates of job formation and level of employment are much higher in Moscow and St. Petersburg than in the rest of the country. Contrary to our expectations, there was not a significant difference between residents of Moscow and St. Petersburg in income dynamic patterns in our multivariate analysis, so we grouped these two metropolitan areas.

In Russia, rural areas have traditionally lagged in their level of income, even under the planned economy of the Soviet era. ${ }^{19}$ The income disparity seems likely to grow based on our results. For the $1992-93$ period, urban households are slightly more likely to be persistently poor 
than rural households. The proportion of poor families in Moscow and St. Petersburg is the lowest. For the second phase of the RLMS, the poverty distribution is reversed; households from the rural areas are more likely to be poor than those from urban and metropolitan areas. Persistent and recurrent poverty in rural areas are six times more common than in Moscow and St. Petersburg and about $60 \%$ more common than in the other urban areas of Russia. Among relatively well-off households, the biggest change between 1992-93 and 1994-96 is an increased likelihood that more rich and fewer persistently poor households are found in metropolitan areas.

\section{Employment Status of Household Head}

There are surprisingly small differences based on the employment status of the household head. In both samples of the survey, the probability of being persistently poor for households with unemployed heads is slightly higher among families with an employed head.

Overall there are strong differences between the 1992-93 and the 1994-96 phases of the economic reform process. First, there is an obviously increased polarization in almost all categories of poverty. For example, if in rounds 1-4 (table 1a) the probability of being persistently poor for households with a high-school-educated head was approximately $60 \%$ higher than the probability for families headed by a university graduate, in the second sample, the ratio of probabilities is equal to 2. The likelihood of being persistently poor for families from rural regions of Russia is eight times higher than for households from Moscow and St. Petersburg in rounds 5-7, and only $65 \%$ higher in rounds $1-4$.

\section{Chronically Poor}

We focus further on the persistently poor group and examine the significant education-demographic category relationships (fig. 5). Figure 6 shows the distribution of persistently poor Russians by type of settlement for selected demographic categories. Figures 5 and 6 present the simulations for education and type of settlement. There is a strong relationship between the education level of the household head and the incidence of chronic poverty. For the panel representing rounds $1-4$, families headed by single parents with a high school education or less are almost twice as likely to be persistently poor as those headed by a university graduate. The same relationship between poverty and education exists among nuclear families. Here, the likelihood of persistent poverty is more than three times higher for households headed by someone with only a highschool education than it is for families headed by a university-degree holder. Analogous relationships are shown for households in rounds 57 (fig. $5 b$ ).

Equally significant relationships exist between type of residence and these demographic categories. Families headed by single parents from 
(a) Rounds 1-4

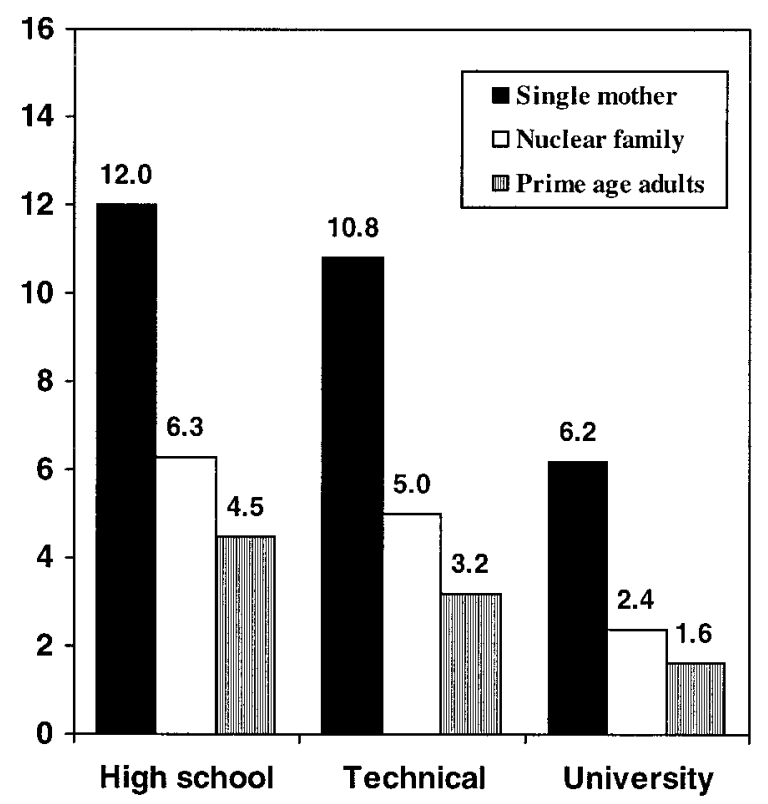

(b) Rounds 5-7

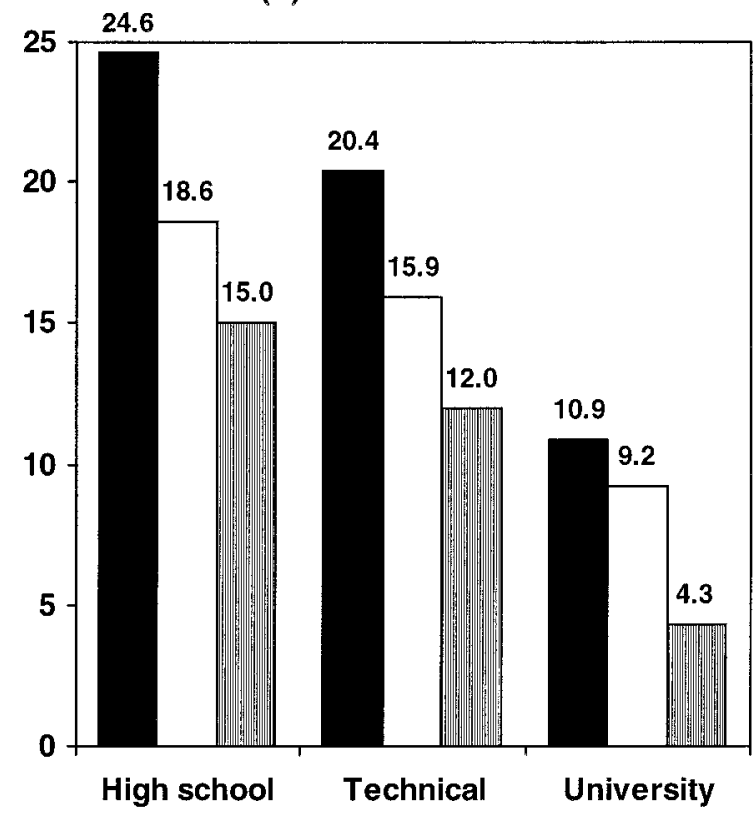

FIG. 5.- Simulation. Proportion of persistently poor among households headed by persons with different levels of education: (a) RLMS rounds 1-4 (September 1992-November 1993); (b) rounds 5-7 (December 1994-October 1996). 
(a) Rounds 1-4

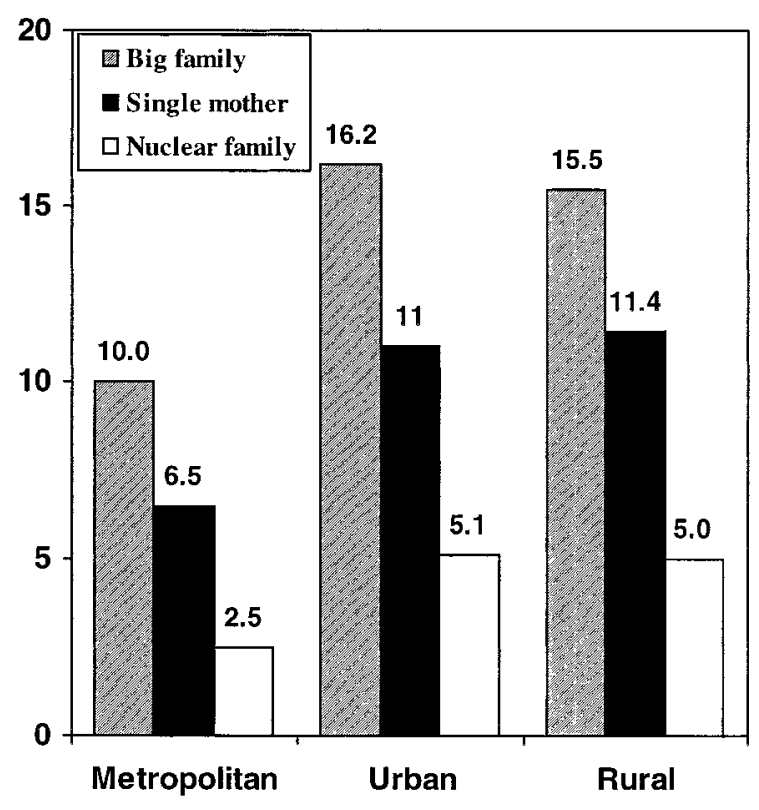

(b) Rounds 5-7

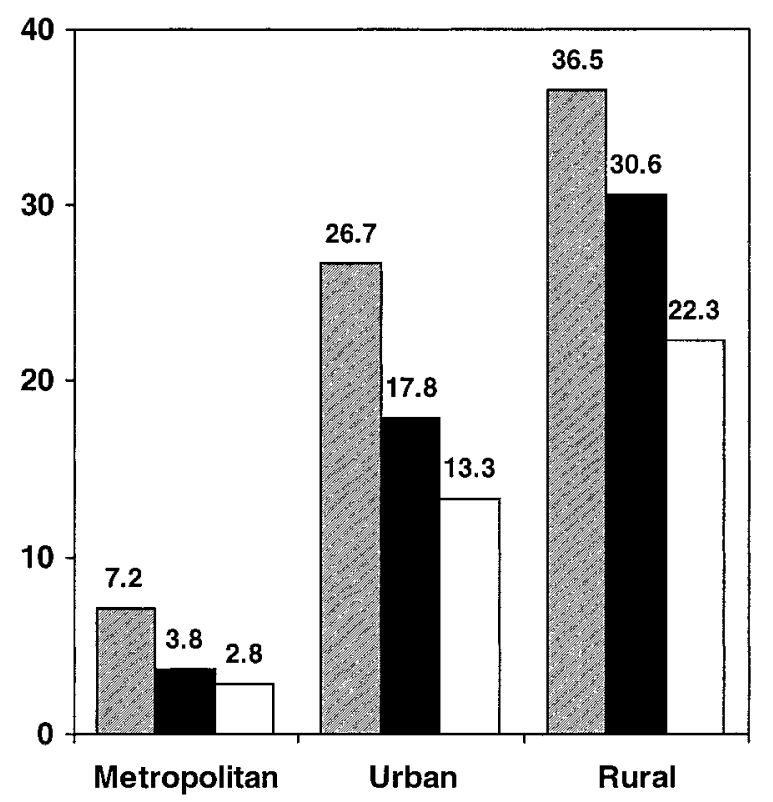

FIG. 6.- Simulation. Proportion of persistently poor among households with different residence types: (a) RLMS rounds 1-4 (September 1992-November 1993); (b) rounds 5-7 (December 1994-October 1996). 
Russia's rural population is almost four times more likely to be persistently poor than its urban population. Similar patterns hold for families with more than two children. Data from rounds 5, 6, and 7 demonstrate the same patterns, but the contrast between urban and rural areas is even more marked.

\section{Discussion}

The current set of social protection institutions developed in the former Soviet Union has not provided a meaningful level of protection against poverty during this difficult period of reform. The reform process has affected all groups in Russia. However, selected groups have experienced quite different patterns of earning. It is our view that there are groups that are affected mainly by macroeconomic shocks and others that require more thorough attention to the long-term structural relationships that affect their income-earning capacity. For example, wage arrears or high inflation in certain months can temporarily bring the income of a household with working adults below the poverty line, but for families with single parents even stable wage payments would not be enough to satisfy basic needs.

Figure $7 a$ shows the distribution of the Russian poor by type of income dynamics for phase 1 of the RLMS. The composition of the poor varies significantly across the rounds of the survey. Over these four rounds, $18 \%-33 \%$ of poor families were occasionally poor. We suppose that the main reason this type of household experiences poverty is related to macrochanges in the Russian economy. High inflation, arrears in wage and pension payments, and large fluctuations in exchange rates could be the factors that influenced these families' incomes. As shown in the first part of this article, the volatility of income is the highest for such households.

In contrast, for the groups of population that we designated as persistently or recurrently poor, the stochastic macrocomponent presumably was not the principal determinant of their income status. Analysis suggests that microeconomic factors played a far greater role in the process of income formation for these households. As we showed above, socioeconomic characteristics of persistently and recurrently poor households are important factors affecting the probability that these families will experience poverty. Education of the household head, type of settlement, and household demographic category have the highest significance in defining income status for the chronically poor.

Figure $7 b$ shows the distribution of poor Russian households by our longitudinal categories of poverty. As in the first phase of the survey (fig. $7 a$ ), we observe heterogeneity in the dynamic structure of the Russian poor over this period. A significant proportion of the population was persistently poor during phase 2 of the RLMS. At the same time, more than 
(a) Rounds 1-4

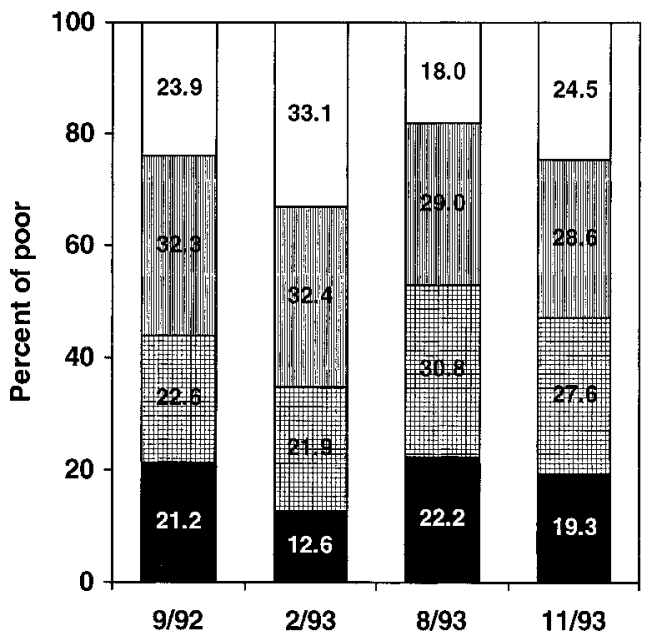

\section{Dersistently poor 困 Recurrently poor \\ 四 Transitionally poor $\square$ Occasionally poor}

(b) Rounds 5-7

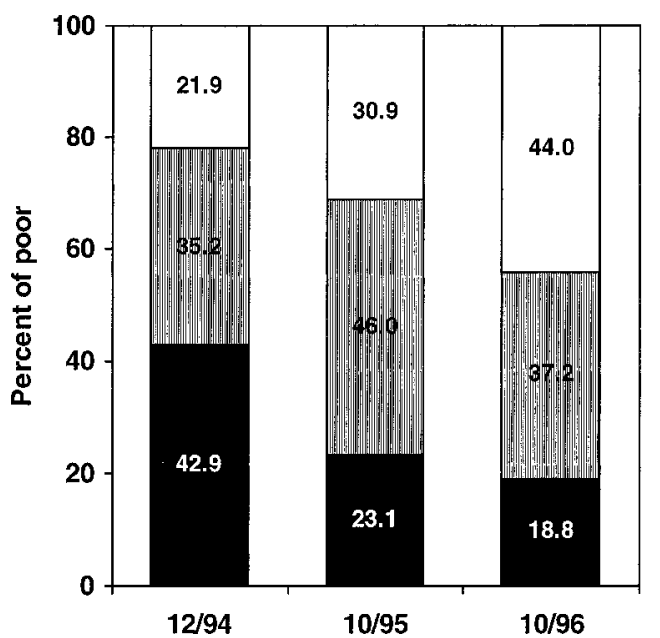

\section{Persistently poor \\ ㅁiㅁ Transitionally poor}

$\square$ Occasionally poor

FIG. 7.-(a) Distribution of Russian poor by type of income dynamic, RLMS rounds 1-4 (September 1992-November 1993); (b) Distribution of Russian poor by type of income dynamic, RLMS rounds 5-7 (December 1994-October 1996). 
a third of the poor households in each round were occasionally poor overall.

In addition, it is clear that the composition of the Russian poor in these last 2 years is different from that in 1992-93. There is a twofold increase in the number of new households entering the ranks of the poor from round 5 to round 7 , and there is a corresponding decrease in the proportion of persistently poor.

The sharp rise in poverty during 1994-96 explains a shift from the relatively stable percentage of persistently poor in the 1992-93 sample to the declining share of the persistently poor in the 1994-96 sample. The shift may point to the beginning of a new stage in the transition of the Russian economy. The high level of unemployment and the decline in the level of government subsidies are two factors associated with the new households that joined the ranks of the poor during the last two years of the survey. Research is needed to understand this dynamic situation.

Data related to the demographic factors associated with poverty from 1994-96 also show that the nature of poverty has changed. A number of actors such as residents in rural and urban areas other than Moscow and St. Petersburg are much more likely to be linked with persistent poverty in this 2-year period as compared to the 1992-93 period.

Overall, these results allow us to divide all Russian poor into three groups by the type of factors affecting their income status. The first group comprises households for which the fluctuations in family income can be explained mostly by changes in the macroeconomic conditions. These households are categorized as occasionally and transitionally poor in phase 1 , and occasionally poor in phase 2 . For such families, preventive policy measures should be designed that will secure minimum family income in case of rapid changes in the macroeconomic environment. Two important options may be developing policy measures that would fill the financial gap by allowing temporarily poor households to smooth their consumption needs by borrowing toward the future and repaying the debt in periods of relative prosperity and using a system of financial institutions that would provide low-interest loans.

Income of the households from the second group, those households that are recurrently poor in phase 1 and transitionally poor in phase 2 , is affected by macro- and microeconomic changes in family living conditions. Policies to eradicate poverty for such households should combine measures to prevent and alleviate poverty. These measures should also focus on financial support of poor households and on the improvement of employment prospects for working family members and the increase of earned income.

But it is the third group, the persistently poor, to whom special attention must be paid. Moreover, as Duncan et al. note, "It is vital that programs aimed at curing long-term poverty make such a distinction, 
based on knowledge of both who among the poor is most likely to remain poor as well as who among long-term poor would profit the most from these programs. It makes little sense to devote scarce resources to provide job training for someone who would have found a job quickly in any case." 20

The group facing persistent poverty should be most heavily targeted by a system of programs aimed at eliminating the causes of their poverty. These households are less likely to come out of poverty without essential government subsidies and other structural remedies such as job training and counseling. As we showed in the first part of this article, many chronically poor families are unable to cover even half of their basic needs. Much more radical measures in comparison to aid for other forms of poverty are needed to help the permanently poor households meet minimum requirements. Government intervention on structural and personal levels is needed to decrease the risk of Russian families falling into permanent poverty. This intervention should combine financial support of households through subsidies (monetary and in-kind) with measures aimed at changing the structure of the labor market allow to stable employment opportunities for members of poor households.

It is clear that the nature of economic changes in Russia has had a great deal to do with the current structure of income. The most rapid growth of the private sector is in Moscow and St. Petersburg. Unless there is a major shift in the nature of the economic change in Russia, the gap between these regions and the rest of the country will only grow.

The results presented above should not be viewed as definitive either in the categorization of the Russian poor or in providing unambiguous policy guidelines. They are best viewed as useful documentation of empirical regularities - the so-called stylized facts of longitudinal survey experience. They can also be viewed as providing an introduction to the study of poverty and income dynamics in the post-Soviet era in Russia.

The dynamic nature of poverty and the fact that most of the Russian households classified as poor by previous research are only temporarily poor must be understood. These families move into and out of poverty, which makes it possible to develop a new set of policies that aim for poverty prevention rather than alleviation. We show that there are many kinds of poverty rather than just one. Different groups of poor coexist in Russian society, and their responses to social and economic shocks are essentially different. New models for analyzing the reasons for and causes of poverty can be used to construct fine-tuning antipoverty policies that will target differently every category of the poor.

The new social security system should be designed to be welladapted to the high risk of household financial hardship faced by Russian families, and new proactive measures should be developed to prevent poverty as well as to bring a poverty spell to an end more quickly. Under 
conditions of scarce financial and administrative resources, the problem of the efficiency of the social safety nets becomes very important. The problem of protecting the most vulnerable low-income groups of the Russian population cannot be solved without creating policy mechanisms that target this group.

To summarize the discussion above, the following conclusions can be drawn:

1. The poor are a heterogeneous group with different types of poverty coexisting in Russian society.

2. Only a small percentage of the Russian families experiencing poverty during the reform period are persistently poor, while a large part of the population moves in and out of poverty.

3 . The persistently poor in Russia not only experience the longest poverty spells, but they also have the lowest income and the smallest probability of escaping poverty.

4. Groups with the highest volatility of income (those more affected by macrochanges in the economy) are the transitionally and occasionally poor.

5. There is a large component of the population whose income is sufficient to cover basic needs.

6. Heterogeneity of the Russian poor is reflected in the differences in major factors affecting the process of income formation among subgroups of the poor.

7. Families headed by single parents and families with three or more children are overrepresented in low-income groups, especially among the persistently poor.

8. Contrary to the prevailing view in Russia, ${ }^{21}$ the income of pensioners is relatively high and the probability of being poor for families of pensioners is low.

9. The majority of Russian children are affected by poverty. 
TABLE A1

Pooled Sample Probit Estimation with a Control for Unobserved HETEROGENEITY

\begin{tabular}{|c|c|c|c|}
\hline & Coefficient & $\begin{array}{l}\text { Standard } \\
\text { Error }\end{array}$ & $t$-ratio \\
\hline \multicolumn{4}{|l|}{ Rounds 1-4, September 1992-November 1993: } \\
\hline \multicolumn{4}{|l|}{ Demographic categories: } \\
\hline Number of children in the household & .207 & .072 & 2.890 \\
\hline Number of pensioners in the household & -.313 & .032 & -9.875 \\
\hline Single parent family & .178 & .057 & 3.118 \\
\hline Family of pensioner & -.348 & .084 & -4.126 \\
\hline Family with more than three children & -.128 & .094 & -1.370 \\
\hline Nuclear family & -.322 & .050 & -6.408 \\
\hline Family of prime-age adults & -.171 & .052 & -3.289 \\
\hline Other families & \multicolumn{3}{|c|}{ Reference } \\
\hline \multicolumn{4}{|l|}{ Reference categories: } \\
\hline \multicolumn{4}{|l|}{ Employment status: } \\
\hline Family with unemployed household head & .506 & .058 & 8.736 \\
\hline \multicolumn{4}{|l|}{ Educational level of household head: } \\
\hline High schoool & .207 & .074 & 2.792 \\
\hline Technical or vocational & .166 & .063 & 2.624 \\
\hline University or higher & \multicolumn{3}{|c|}{$.100 \quad \begin{array}{l}.003 \\
\text { Reference }\end{array}$} \\
\hline \multicolumn{4}{|l|}{ Type of residence: } \\
\hline Metropolitan area & -.186 & .061 & -3.033 \\
\hline Other urban areas & -.119 & .075 & -1.594 \\
\hline Rural areas & \multicolumn{3}{|c|}{ Reference } \\
\hline \multicolumn{4}{|l|}{ Age of household head: } \\
\hline $18-23$ years old & -.770 & .119 & -6.451 \\
\hline $23-30$ years old & .055 & .093 & .594 \\
\hline $30-45$ years old & \multicolumn{3}{|c|}{ Reference } \\
\hline $45-60$ years old & .311 & .084 & 3.723 \\
\hline $60+$ years old & .127 & .073 & 1.725 \\
\hline \multicolumn{4}{|l|}{ Time dummies: } \\
\hline Round 1 & -.046 & .036 & -1.306 \\
\hline Round 2 & .413 & .034 & 12.229 \\
\hline Round 3 & -.119 & .036 & -3.316 \\
\hline Round 4 & \multicolumn{3}{|c|}{ Reference } \\
\hline \multicolumn{4}{|l|}{ Interaction terms: } \\
\hline Metro and high school & -.919 & .115 & -7.985 \\
\hline Metro and technical & -.897 & .094 & -9.594 \\
\hline Other urban and high school & -.826 & .086 & -9.581 \\
\hline Other urban and technical & -.744 & .083 & -8.984 \\
\hline$\rho$ & .411 & & \\
\hline Log-likelihood function & -6463.140 & & \\
\hline \multicolumn{4}{|l|}{ Rounds 5-7, December 1994-October 1996: } \\
\hline \multicolumn{4}{|l|}{ Demographic categories: } \\
\hline Number of children in the household & .140 & .132 & 1.059 \\
\hline Number of pensioners in the household & -.262 & .037 & -7.093 \\
\hline Single mother & .154 & .088 & 1.748 \\
\hline Family of pensioners & -.323 & .105 & -3.069 \\
\hline Family with more than three children & -.044 & .141 & -.314 \\
\hline Nuclear family & -.150 & .069 & -2.177 \\
\hline Family of prime-age adults & -.137 & .066 & 2.085 \\
\hline & \multicolumn{3}{|c|}{ Reference } \\
\hline \multirow{2}{*}{\multicolumn{4}{|c|}{ Reference categories: }} \\
\hline Employment status: & & & \\
\hline Family with unemployed head & .554 & .079 & 7.036 \\
\hline
\end{tabular}


TABLE A1 (Continued)

\begin{tabular}{|c|c|c|c|}
\hline & Coefficient & $\begin{array}{l}\text { Standard } \\
\text { Error }\end{array}$ & $t$-ratio \\
\hline \multicolumn{4}{|c|}{ Educational level of household head: } \\
\hline High schoool & .069 & 057 & 1.204 \\
\hline Technical or vocational & -.055 & .068 & -.813 \\
\hline University or higher & \multicolumn{3}{|c|}{ Reference } \\
\hline \multicolumn{4}{|l|}{ Type of residence: } \\
\hline Metropolitan area & -1.147 & 140 & -8.208 \\
\hline Other urban areas & -.647 & .068 & -9.562 \\
\hline Rural areas & \multicolumn{3}{|c|}{ Reference } \\
\hline \multicolumn{4}{|l|}{ Age of household head: } \\
\hline $18-23$ years old & -.131 & .099 & -1.323 \\
\hline $23-30$ years old & -.080 & .058 & -1.390 \\
\hline $30-45$ years old & \multicolumn{3}{|c|}{ Reference } \\
\hline $45-60$ years old & -.177 & .044 & -4.004 \\
\hline $60+$ years old & .003 & .099 & .035 \\
\hline \multicolumn{4}{|l|}{ Time dummies: } \\
\hline Round 5 & -.263 & 039 & -6.821 \\
\hline Round 6 & .036 & .038 & .954 \\
\hline Round 7 & \multicolumn{3}{|c|}{ Reference } \\
\hline \multicolumn{4}{|l|}{ Interaction terms: } \\
\hline Metro and high school & .096 & .190 & .504 \\
\hline Metro and technical & 474 & .193 & 2.455 \\
\hline Other urban and high school & 464 & .081 & 5.716 \\
\hline Other urban and technical & .503 & .091 & 5.518 \\
\hline$\rho$ & 0.378 & & \\
\hline Log-likelihood function & -4069.608 & & \\
\hline
\end{tabular}

\section{Notes}

* Our calculations were made with a program kindly supplied to us by Dr. David Guilkey.

1. Anthony Barnes Atkinson and John Micklewright, Economic Transformation in Eastern Europe and the Distribution of Income (Cambridge: Cambridge University Press, 1992), p. 4.

2. Thomas A. Mroz and Barry M. Popkin, "Poverty and the Economic Transition in the Russian Federation," Economic Development and Cultural Change 44 (1995): 1-31.

3. Victor George and Irving Howards, Poverty amidst Affluence: Britain and the United States (Aldershot: Elgar, 1991).

4. See the RLMS website for detailed data on the survey and instruments and ways to obtain the data set at no cost. The World Wide Web address for the Russia Longitudinal Monitoring Survey is http://www.cpc.unc.edu/projects/ rlms/rlms home.html.

5. Mervyn Matthews, Poverty in the Soviet Union (Cambridge: Cambridge University Press, 1986).

6. N. M. Rimashevskaya, "Nash prozhitochnyi minimum" [Our subsistence minimum], Sotsialisticheskii trud [Socialist Labor] 8 (1990): 23-38.

7. Barry M. Popkin, Marina Mozhina, and Alexander K. Baturin, "The Development of a Subsistence Income Level in the Russian Federation"' (Chapel Hill: University of North Carolina, Carolina Population Center, 1992).

8. Barry M. Popkin, Alexander K. Baturin, Marina Mozhina, and Thomas Mroz with the assistance of Anna Safronova, Igor Dmitrichev, Elena Glinskaya, 
and Michael Lokshin, “The Russian Federation Subsistence Income Level: The Development of Regional Food Baskets and Other Methodological Improvements." Report to the World Bank and Ministry of Labor and Ministry of Social Protection Paper, Russian Federation (Chapel Hill: University of North Carolina, Carolina Population Center, 1995).

9. Richard Coe, "Dependency and Poverty in the Short and the Long Run,' Accounting for Race and Sex Differences in Earnings and Other Analyses of the First Nine Years of the Panel Study on Income Dynamics, ed. Greg J. Duncan and James N. Morgan, vol. 6., Five Thousand American Families: Patterns of Economic Progress (Ann Arbor: University of Michigan, Institute for Social Research, 1978); Greg J. Duncan, Richard D. Coe, and Martha S. Hill, "An Overview of Family Economic Mobility," Years of Poverty, Years of Plenty, ed. Greg J. Duncan (Ann Arbor: University of Michigan, Institute for Social Research, 1984), pp. 9-32; Martha S. Hill, "Some Dynamic Aspects of Poverty," Analyses of the First Twelve Years of the Panel Study of Income Dynamics, ed. Martha S Hill, Daniel H. Hill, and James N. Morgan, vol. 9, Five Thousand American Families: Patterns of Economic Progress (Ann Arbor: University of Michigan, Institute for Social Research, 1981); Frank Levy, "How Big Is the American Underclass?', Working Paper 0090-1 (Washington D.C.: Urban Institute, 1977); Lee Rainwater, "Persistent and Transitory Poverty: A New Look,' working paper no. 70 (Cambridge, Mass.: Joint Center for Urban Studies of MIT and Harvard University, 1981).

10. Mary Jo Bane and David T. Ellwood, "Slipping into and out of Poverty: The Dynamics of Spells," Journal of Human Resources 21, no. 1 (1986): 1-23; Robert Walker in association with Karl Ashworth, Poverty Dynamics: Issues and Examples (Aldershot: Avebury, 1994).

11. Mroz and Popkin (n. 2 above).

12. Bane and Ellwood; Patricia Ruggles and Roberton Williams, Measuring the Duration of Poverty Spells, Survey of Income and Program Participation Working Paper Series 8909 (Washington, D.C.: Urban Institute, 1989).

13. Greg J. Duncan, Bjorn Gustafsson, Richard Hauser, Gunther Schmauss, Hans Messinger, Ruud Muffels, Brian Nolan, and Jean-Claude Ray, "Poverty Dynamics in Eight Countries," Journal of Population Economics 6 (1993): 215-34, see p. 228.

14. Walker (n. 10 above).

15. Duncan et al. (n. 13 above).

16. Yair Mundlak, "On the Pooling of Time Series and Cross Sectional Data," Econometrica 46 (1978): 69-86.

17. G. S. Maddala, Limited Dependent and Qualitative Variables in Econometrics (Cambridge: Cambridge University Press, 1983).

18. Ibid.

19. Atkinson and Micklewright (n. 1 above).

20. Duncan et al. (n. 13 above), p. 219.

21. Vladimir Mikhalev, "Social Security in Russia under Economic Transformation"' Europe-Asia Studies 48, no. 1 (1996): 5-25. 